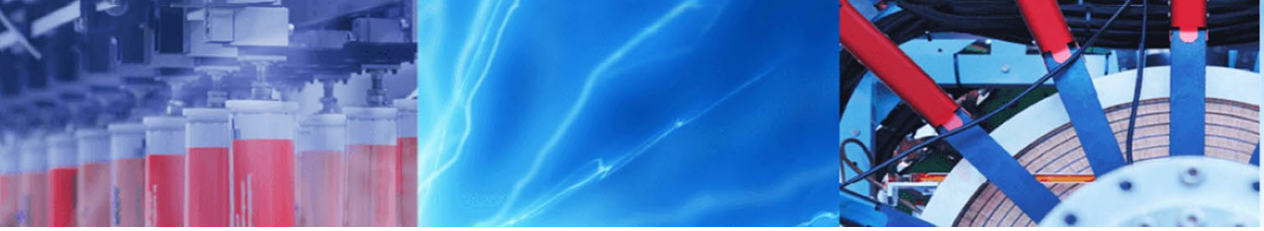

Research Article

\title{
Determination of parameters affecting aerodynamic performance in S833 airfoil
}

\author{
Burak Çanakçi ${ }^{1}$ Uğur Çakir ${ }^{1}$ Ayhan Aytaç ${ }^{1} \mathbb{D}$
}

Received: 21 January 2020 / Accepted: 23 October 2020 / Published online: 11 November 2020

(c) Springer Nature Switzerland AG 2020

\begin{abstract}
This study presents the investigation of the factors affecting the performance of the airfoil, which is supposed to be used in a low power wind turbine. Airfoil surface roughness, angle of attack and wind speed parameters and interactions between these parameters affect performance. The conditions that the airfoil will be exposed to in the field of use can be modeled in the wind tunnel beforehand, and its performance in working conditions can be predicted. For this purpose, the airfoil model prepared using a three-dimensional printer can be tested in the wind tunnel, and the most effective parameter on performance can be determined. With the factorial design method used differently from the literature, performance analysis can be performed without the need for long mathematical calculations and analyzes. As a result, the most effective parameter on the performance is found as the surface roughness from the experimental design model created according to the selected factor levels. The second important parameter is the angle of attacksurface roughness binary factor interaction.
\end{abstract}

Keywords $\mathrm{S} 833$ airfoil $\cdot C_{L} / C_{D}$ ratio $\cdot 2^{\mathrm{k}}$ factorial design $\cdot$ Aerodynamic performance Surface roughness

\section{Introduction}

The first and most important factor that makes these turbines operate in the most efficient way is the shape of the airfoil to be used in the design. The conditions under which a wind turbine with a design phase has been completed will have to be taken into account in order to be able to work most efficiently during its lifetime. Due to environmental influences such asinsect adhesion, dust, dirt, frost, corrosion, etc., disruption and roughness of the turbine airfoils are formed. However, contrary to expectations, roughness can also lead to an increase in wing performance in some cases. There are many studies in the literature on the determination of parameters that are effective on airfoil performance.

Since the contamination effect on the wing is the primary influencing factor on performance, most studies have focused on this issue. Environmental influences such as sand storms or icing on the wing surfaces cause deterioration of the wing surface quality. Impairments and roughness increases in airfoil surfaces increase aerodynamic resistance and consequently cause reducing turbine power [1-3]. These impurities have been modeled and investigated on the surface of the models created in wind tunnels (eg NACA 63-418 airfoil etc.) in order to realize the difficulties caused by the examination of these deterioration and wear in real conditions and to take measures against these effects [4]. It is an important alternative in numerical methods in performance analysis to eliminate the difficulties created by experimental conditions. In a numerical study, it has been determined that the rains that are large enough to cover the surface of the airfoil have little effect on the performance and the rains at low frequencies change the performance [5]. In a

Ayhan Aytaç, aytac@kho.edu.tr; Burak Çanakçi, bcanakci@kho.edu.tr; Uğur Çakir, ugurcakir@ymail.com | ${ }^{1}$ National Defense University, $\mathrm{KHO}$, Ankara, Turkey. 
study on the NACA 6 series airfoils, the level of contamination on the surface was changed from the front edge to the rear edge and a reduction in lift coefficient up to $35 \%$ was observed in the critical angle of attack [6]. As it can be understood from here, most of the recent research has been concerned with the regions and at what rate rather than the occurrence of pollution. In numerical and experimental researches on the roughness effect occurring at different positions on different airfoils such as DU 95-W-180, DU 96-W-180, the increase in the leading edge roughness has decreased performance $[7,8]$. In the examinations carried out on the NACA 63-415, NACA 23012 and E387 airfoils, sensitive areas leading to loss of performance against roughness were determined and did not affect the performance after a certain roughness value. In fact, it has been determined that certain roughness values added to the airfoil bottom surface provide an increase of $8.62 \%$ in the buoyancy [9-11].

In addition to roughness, there are different parameters affecting aerodynamic performance. For example, how an object in the flow field is affected by a different object in the same flow field and flow direction. NACA 2415, NACA 0012 series were investigated how the performance of the blades changed with the cylindrical rods placed within the same flow area and at certain distances to the front of the wing in the direction of the flow. As a result of the control of flow separation with the CFD simulations carried out, friction reductions of up to $61 \%$ have been achieved, thus an increase in airfoil performance $[12,13]$. Another innovative method that can be used to investigate these factors is artificial neural network method. Using this method, optimal results can be achieved with a neural network model to be established without much experimentation. In the study investigating the effect of a cylinder placed in the same flow area with the NACA 0012 airfoil on the wing performance with ANNs (the ANN artificial neural networks) method; parameters such as cylinder diameter, distance between cylinder and wing were simulated numerically with the neural network model and in the optimized conditions, the $C_{L} / C_{D}$ ratio (the $C_{L}$ dimensionless lift coefficient, the $C_{D}$ dimensionless drag coefficient) increased by $178 \%$ [14].

In our study, a performance analysis method different from the methods mentioned above was used. Statisticalbased experimental design techniques are widely used to investigate and improve the effects of the effects of different parameters on process performance. The main difference that separates the study from the literature surveys mentioned above is that full factorial experimental design method has been used. Full factorial experiments are used to accurately evaluate the main and quadratic interaction effects of experimental factors on target compounds [15]. Thus, the full factorial experimental design gives a more practical and reliable result than fractional factorial experiments such as Taguchi [16]. Factorial design is also advantageous in terms of investigating interactions or changes between factors [17]. The most important factor that distinguishes factorial designs from internal designs is that all of the levels of any factor used in the experiment are identical at each level of other factors [18]. As it is here, in cases where two or more factors are handled, factorial design is a powerful technique.

When each replay is completed in a factorial experiment, all possible combinations of all levels of all factors are examined. The effect of a factor is defined as the change in factor level composed by the response. This is the main effect. Factorial experiments are the only way to determine the interaction between variables [19].

In the literature, there is no study on the airfoils performance analysis using factorial experimental design method. A new model was defined by minimizing the effects of uncontrolled factors. The accuracy of the model was confirmed by verification experiments. This study is original in the literature as the first study in which the full factorial experimental design method is used in the analysis of the airfoil performance analysis.

In the study, firstly, performance parameters of the airfoils are mentioned. Then, the production stages of the airfoil selected for analysis are explained and the experimental setup is introduced. The regression equation obtained from the experimental results performed according to the last experimental design matrix has been revealed, the interaction analyzes of the parameters have been made and the verification experimental results have been presented.

\section{Materials and methods}

In this study, the $\mathrm{S} 833$ airfoil developed by the National Renewable Energy Laboratory (NREL), which is intended to be used in a low-power wind turbine, has beenused. The whole surface of the airfoil was covered with $2 \mathrm{~mm}$. thick coating material to model the contamination that the airfoil is exposed to under operating conditions. Rough and smooth airfoils under the same conditions were subjected to tests at different wind velocities and angle of attack in the subsonic wind tunnel. By using 2-level full factorial experimental design model, the effects of surface roughness, angle of attack and wind speed parameters on aerodynamic performance and interaction between parameters were investigated. 
Fig. 1 S833 airfoil geometry

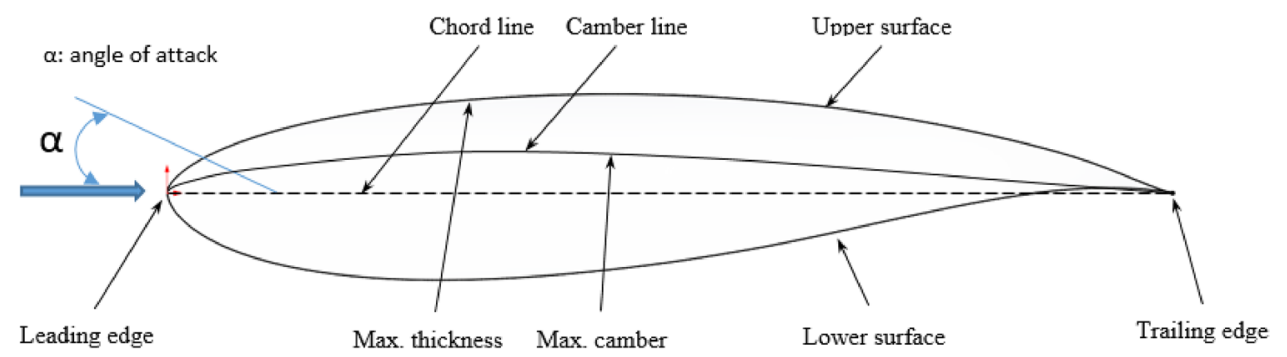

\subsection{Aerodynamic performance parameters of airfoils}

As the current on the airfoils is often close to twodimensional, it is sufficient to examine the flow properties around the flow around a single cross-section as the flow characteristics remain the same in all sections along the airfoil [20]. Airfoil cross-sectional geometry is shown in Fig. 1.

2 force (drag-carry or lift) component and 1 moment (pitching moment) component are acting on the airfoil. The lift force and pitching moment are generally dependent on the pressure distribution across the airfoil surface. The drag force depends on both the pressure and friction distribution along the surface. Because of the different shapes and dimensions of the airfoils developed for various purposes, dimensionless coefficients are taken into consideration in the comparisons and evaluations [20].

$C_{L}$ eq. (1) and $C_{D}$ eq. (2) taken into account in the performance evaluation of the airfoils were calculated in two dimensions as follows. Other terms in the equation are $L$ (the $L$ lift force), $D$ (the $D$ drag force), $V$ (the $V$ wind speed), $\rho$ (the $\rho$ fluid density), $S$ (the $S$ airfoil surface area). After calculating these coefficients without dimension, the $C_{L} / C_{D}$ ratio can be used practically for performance comparisons [20].

$$
\begin{aligned}
& C_{L}=\frac{L}{(1 / 2) \rho V^{2} S} \\
& C_{D}=\frac{D}{(1 / 2) \rho V^{2} S}
\end{aligned}
$$

\subsection{Modeling and production of S833 airfoil}

S833 airfoil used in experimental studies had $200 \mathrm{~mm} \times 200 \mathrm{~mm}$. size was developed by NREL using coordinates was a computerized model and Fortus 250 MC 3D Printer is produced with ABS material (Fig. 2). The airfoil is connected to the wind turbine by a metal shaft
Fig. 2 Produced airfoil
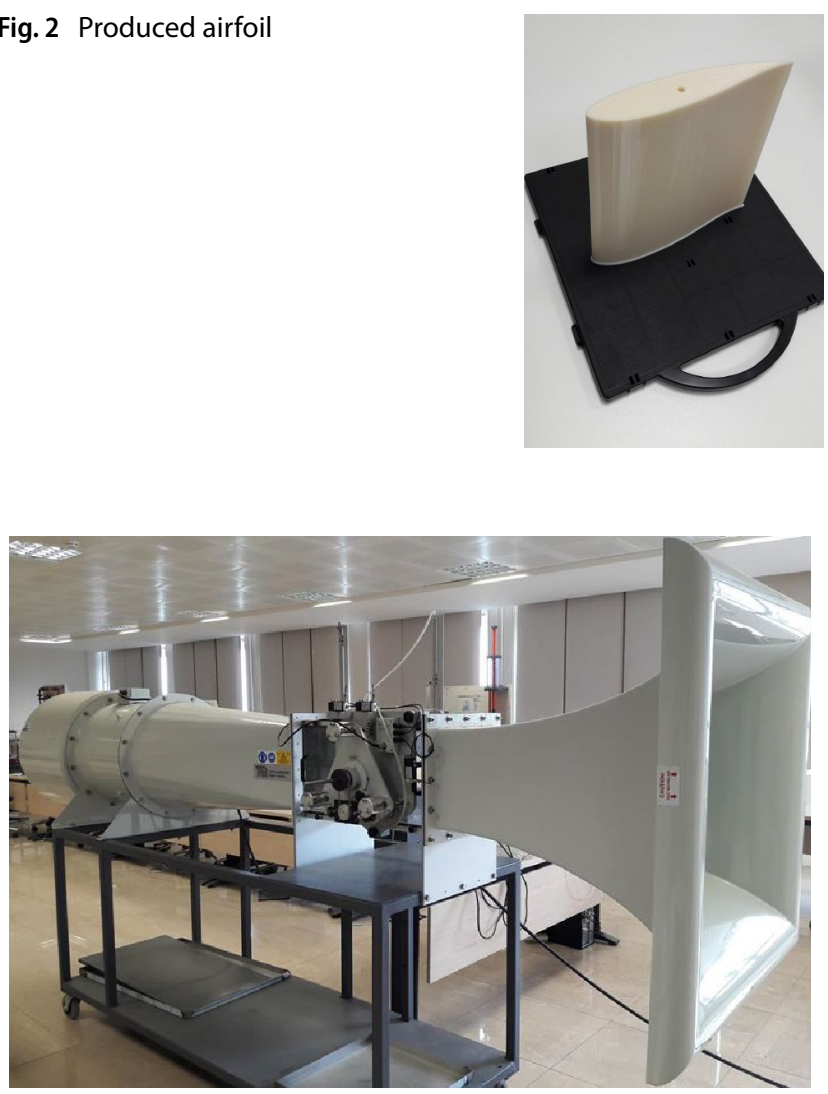

Fig. 3 Wind tunnel

of $11 \mathrm{~mm}$ diameter fixed to the $6 \mathrm{~mm}$. diameter hole on its side surface.

\subsection{Wind turbine and 3-way balancer}

Experimental studies have been carried out in the subsonic wind tunnel TecQuipment AF 100 (Fig. 3) at the maximum wind velocity of $37 \mathrm{~m} / \mathrm{s}$. The tunnel has an inspection section of $300 \times 300 \times 600 \mathrm{~mm}$. The three-component balancer (Lifting Force, Drag Force and Pitching Moment) was used for load measurements. The data measured in the experimental studies were collected by the Versatile Data Acquisition System (VDAS) integrated in the wind tunnel. 
Fig. 4 Coating process applied to the surface of the airfoil
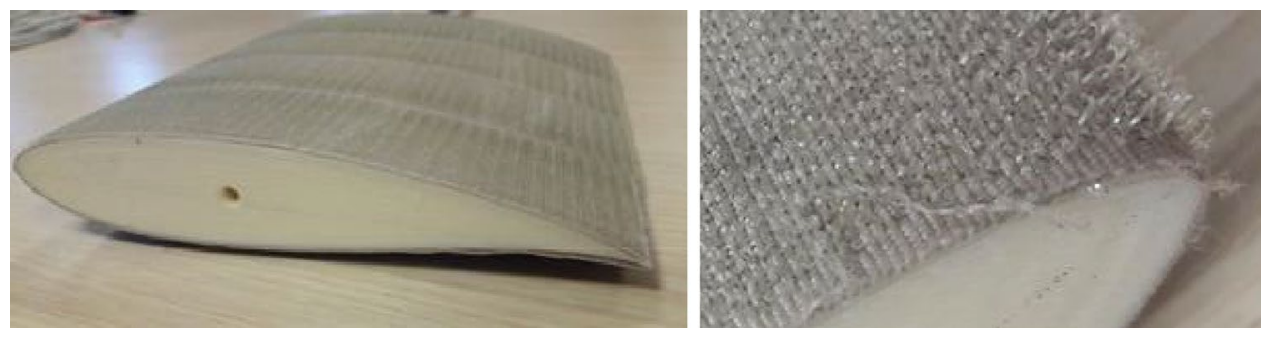

Table 1 Factors and levels

\begin{tabular}{llll}
\hline Factors & Name & Lower level & High level \\
\hline A & Wind speed & $10 \mathrm{~m} / \mathrm{s}$ & $37 \mathrm{~m} / \mathrm{s}$ \\
B & Angle of attack & $5^{\circ}$ & $12^{\circ}$ \\
C & Surface roughness & Clean surface & Coated surface \\
\hline
\end{tabular}

\section{Test results and discussion}

In the first experiments, airfoil was tested at 2 different wind speeds and 2 different angles of attack under clean surface conditions and then $2 \mathrm{~mm}$ thickness coating material simulating surface roughness was applied to the surface of the airfoil (Fig. 4) and the tests were repeated under the same conditions.

As the speed value in the tests, the maximum speed of the wind tunnel is $37 \mathrm{~m} / \mathrm{s}$ and close to the operating conditions $10 \mathrm{~m} / \mathrm{s}$ was used. As an angle of attack, as a result of trials, the aerodynamic performance was highest $12^{\circ}$ and a low angle of attack value of $5^{\circ}$ was selected for comparison. Information for the levels of the selected factors was given in Table 1. $2^{\mathrm{k}}$ factorial (the $2^{\mathrm{k}}$ two level full factorial design) experimental design model was used to examine the parameters effecting the airfoil performance and their interactions with each other. In this design model, wind speed, angle of attack and surface roughness were considered as $k$ (the $k$ factors) parameters. The experimental design matrix was created for the selected two levels of the factors to be investigated, the effect of the airfoil on the performance of $C_{L} / C_{D}$ coefficients. The matrix generated by using the Minitab 18 statistical software program using the coding method was presented in Table 2. In the experiments, lifting, drag forces were collected by VDAS program and $C_{L}$ lifting coefficient, $C_{D}$ drag coefficient and $C_{L} / C_{D}$ ratio were calculated. The test results were given in Table 2 .

\subsection{Regression and variance analysis results}

Multiple regression analysis; As a result of the experiments, backward extraction method was used by using
Table 2 Full factorial experimental design matrix

\begin{tabular}{lllll}
\hline \multirow{2}{*}{$\begin{array}{l}\text { Number of experi- } \\
\text { ments }\end{array}$} & \multicolumn{2}{l}{ Factors and levels (coded) } & \multicolumn{1}{c}{$C_{L} / C_{D}$} \\
\cline { 2 - 4 } & $\mathrm{A}$ & $\mathrm{B}$ & $\mathrm{C}$ & \\
\hline 1 & -1 & -1 & -1 & 2.75 \\
2 & -1 & -1 & +1 & 1.33 \\
3 & -1 & +1 & -1 & 4.62 \\
4 & -1 & +1 & +1 & 1.43 \\
5 & +1 & -1 & -1 & 1.4 \\
6 & +1 & -1 & +1 & 1.25 \\
7 & +1 & +1 & -1 & 4.4 \\
8 & +1 & +1 & +1 & 1 \\
\hline
\end{tabular}

8 values ( $2^{3}$ full factorial) obtained for two levels of each parameter. In the regression analysis, it was aimed to explain the relationship between the variables functionally and to define this relationship with a model [16].

In the first stage, all the main parameters, the binary interactions of the parameters and the interaction caused by the three were included in the model. According to the experimental design matrix established as a result of the analysis performed using the Minitab-18 program; pareto and normal distribution graphs were formed at $a=0.10$ significance level. In the pareto graph analysis for factors and binary interactions, the factors that exceed the threshold value of 2.132, which is the significance level of 0.1 , were the factors that affect the wing performance most. As the graph shows (Fig. 5), the most important factor is the surface roughness, the second important factor is the angle of attack-surface roughness binary interaction and the third important factor is the angle of attack. Factors that have the least effect on the system, wind speed-surface roughness and wind speed-angle of attack are binary factor interactions. These factors with the least effect were not included in the model by the regression analysis program.

In the multiple regression analysis performed using Minitab-18 program, backward extraction method was used by using 8 values ( $2^{3}$ full factorial) obtained for two levels of each parameter as a result of the experiments. In the first stage, all the main parameters, the binary interactions of the parameters and the interaction caused by the three are included in the model. However, in order to 
Fig. 5 Pareto chart of the standardized effects
Pareto Chart of the Standardized Effects

(response is $\mathrm{CL} / \mathrm{CD} ; \alpha=0,1$ )

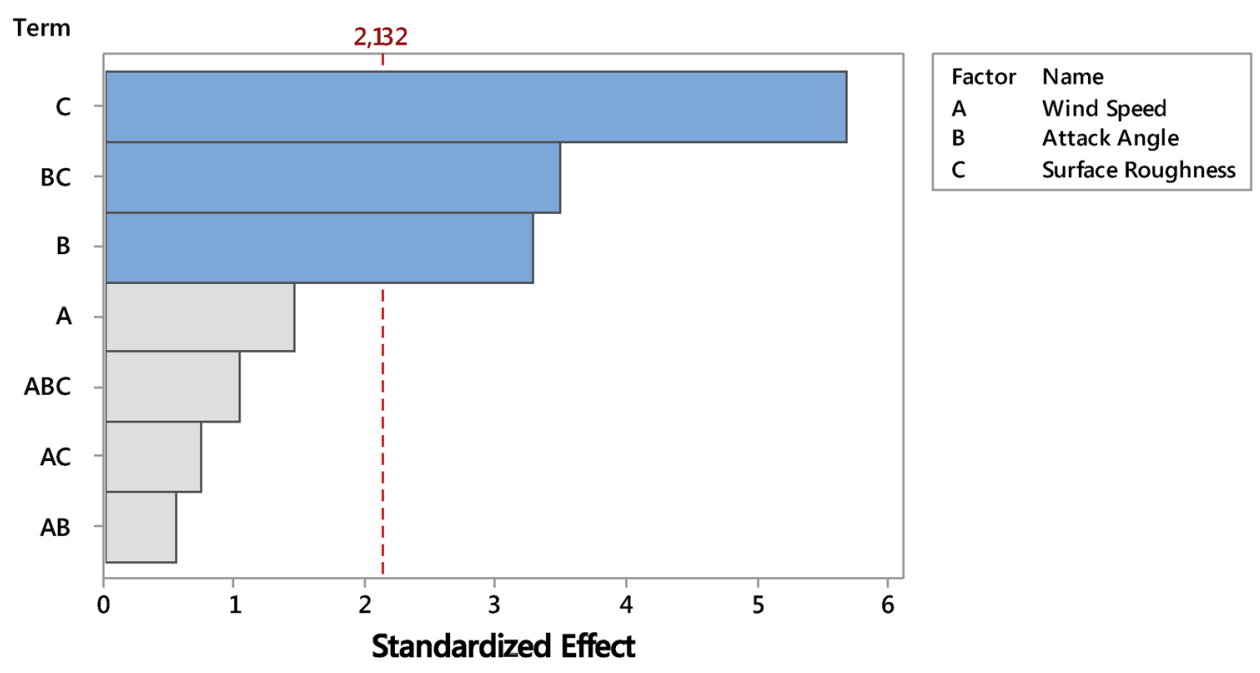

A gray bar represents a term not in the model.

obtain sufficient degree of freedom at the beginning, the step-by-step procedure did not influence the wind speedangle of attack and wind speed-surface roughness of the interactions determined by the binary interactions were not included in the analysis. $a=0.1$ significance level (confidence) according to the $p$ values determined for each factor in the analysis performed step by step; the most effective parameter on wing performance $(p=0.005<0.1)$ was the surface roughness factor. The second important factor was found to be the angle of attack-surface roughness double interaction $(p=0.025<0.1)$. The speed factor, which is the least important factor in the analysis, was removed from the model in step 3. The ratio of the model to the relationship between variables (change in $C_{L} / C_{D}$ ratio) was calculated as $R^{2}=93.26 \%\left(R^{2}\right.$ (corrected)) $\left.=88.2 \%\right)$. The results of the regression analysis were presented in Table 3.
According to the results of the regression analysis, the variance (anova) analysis was performed to analyze the significance of the contribution of each variable to the model at $a=0.1$ significance level. The results of analysis of variance were presented in Table 4. The significance level of the model for the factors was found to be $p=0.008$ and the $F$ test statistic were 18.44 . There were no factors to be excluded from the model when the level of significance of all the factors that constitute the model is examined in the same way. For binary interactions, $p=0.025$ and $F$ were obtained as test statistic 12.22 .

In order to determine the coefficients of regression eq. (3) $t$-test was applied. The results of the $T$-test and the coefficients obtained were presented in Table 5 . The effects of the factors in the model were seen here. Impact values, positive signfactor (angle of attack main factor impact
Table 3 Multiple regression analysis results

\begin{tabular}{|c|c|c|c|c|c|c|}
\hline & \multicolumn{2}{|l|}{ Step 1} & \multicolumn{2}{|l|}{ Step 2} & \multicolumn{2}{|l|}{ Step 3} \\
\hline & Coef & $P$ & Coef & $P$ & Coef & $P$ \\
\hline Constant & 2.273 & & 2.273 & & 2.273 & \\
\hline Wind speed & -0.260 & 0.155 & -0.260 & 0.166 & & \\
\hline Angle of attack & 0.590 & 0.037 & 0.590 & 0.026 & 0.590 & 0.030 \\
\hline Surface roughness & -1.020 & 0.013 & -1.020 & 0.006 & -1.020 & 0.005 \\
\hline Angle of attack $\times$ Surface roughness & -0.628 & 0.033 & -0.628 & 0.022 & -0.628 & 0.025 \\
\hline $\begin{array}{l}\text { Wind speed } \times \text { Angle of attack } \times \text { Sur- } \\
\text { face roughness }\end{array}$ & -0.185 & 0.253 & & & & \\
\hline$S$ & & 0.329014 & & 0.404269 & & 0.507715 \\
\hline$R$-sq & & $98.58 \%$ & & $96.79 \%$ & & $93.26 \%$ \\
\hline$R$-sq (adj) & & $95.04 \%$ & & $92.52 \%$ & & $88.20 \%$ \\
\hline$R$-sq (pred) & & $77.34 \%$ & & $77.20 \%$ & & $73.02 \%$ \\
\hline
\end{tabular}


Table 4 Results of variance analysis

\begin{tabular}{llllll}
\hline Source & DF & Adj SS & Adj MS & F-Value & $P$-Value \\
\hline Model & 3 & 14.258 & 4.7527 & 18.44 & 0.008 \\
Linear & 2 & 11.108 & 5.5540 & 21.55 & 0.007 \\
$\quad$ Angle of attack & 1 & 2.785 & 2.7848 & 10.80 & 0.030 \\
$\quad$ Surface roughness & 1 & 8.323 & 8.3232 & 32.29 & 0.005 \\
$\quad$ 2-way interactions & 1 & 3.150 & 3.1501 & 12.22 & 0.025 \\
$\quad$ Angle of & 1 & 3.150 & 3.1501 & 12.22 & 0.025 \\
$\quad$ attack $\times$ Surface & & & & & \\
$\quad$ roughness & & & & & \\
Error & 4 & 1.031 & 0.2578 & & \\
$\quad$ Total & 7 & 15.289 & & & \\
\hline
\end{tabular}

value $=1.180)$ positive effect on performance, negative sign factors (surface roughness main factor impact value $=-2.040$, angle of attack $\times$ surface roughness binary interaction impact value $=-1.255$ ) reduces performance. In the analyzes, regression equation was obtained including the factors that were found to be effective in performance.

Regression equation:
As can be seen in the analysis and the regression equation obtained, the wind speed factor was not taken into account because of the low confidence level value $(a=0.10)$. However, in order to see the effect of the wind speed parameter, which has a significant effect on the design and selection of wind turbines, on the wing performance, the analysis was repeated by selecting the confidence level $a=0.17$. When the normal distribution of the new analysis and the pareto graphs (Fig. 6) were examined, the speed factor was at the immediate boundary of the 1.798 line which was the threshold value of 0.17 significance level. The most effective factor for the newly installed model was surface roughness and the second important factor was the angle of attacksurface roughness binary interaction.

In the new multiple regression analysis, when the $p$ values obtained in the second step were examined, the most effective factor was the surface roughness while the second important factor was the angle of attack-surface roughness of the double factor interaction (Table 6). For installed model $R^{2}=96.79 \%\left(R^{2}(\right.$ corrected $\left.)=92.52 \%\right)$

$C_{L} / C_{D}=2.273+0.590$ Angle of attack-1.020 Surface roughness -0.628 Angle of attack $\times$ Surface roughness (3)

Table 5 T-test results and regression equation coefficients
Fig. 6 According to the new analysis; pareto chart of the standardized effects

\begin{tabular}{lcccccc}
\hline Term & Effect & Coef & SE Coef & T-Value & $P$-Value & VIF \\
\hline Constant & & 2.273 & 0.180 & 12.66 & 0.000 & \\
Angle of attack & 1.180 & 0.590 & 0.180 & 3.29 & 0.030 & 1.00 \\
Surface roughness & -2.040 & -1.020 & 0.180 & -5.68 & 0.005 & 1.00 \\
Angle of attack $\times$ Sur- & -1.255 & -0.628 & 0.180 & -3.50 & 0.025 & 1.00 \\
$\quad$ & & & & & & \\
\hline
\end{tabular}

\section{Pareto Chart of the Standardized Effects}

(response is $\mathrm{CL} / \mathrm{CD} ; \alpha=0,17$ )

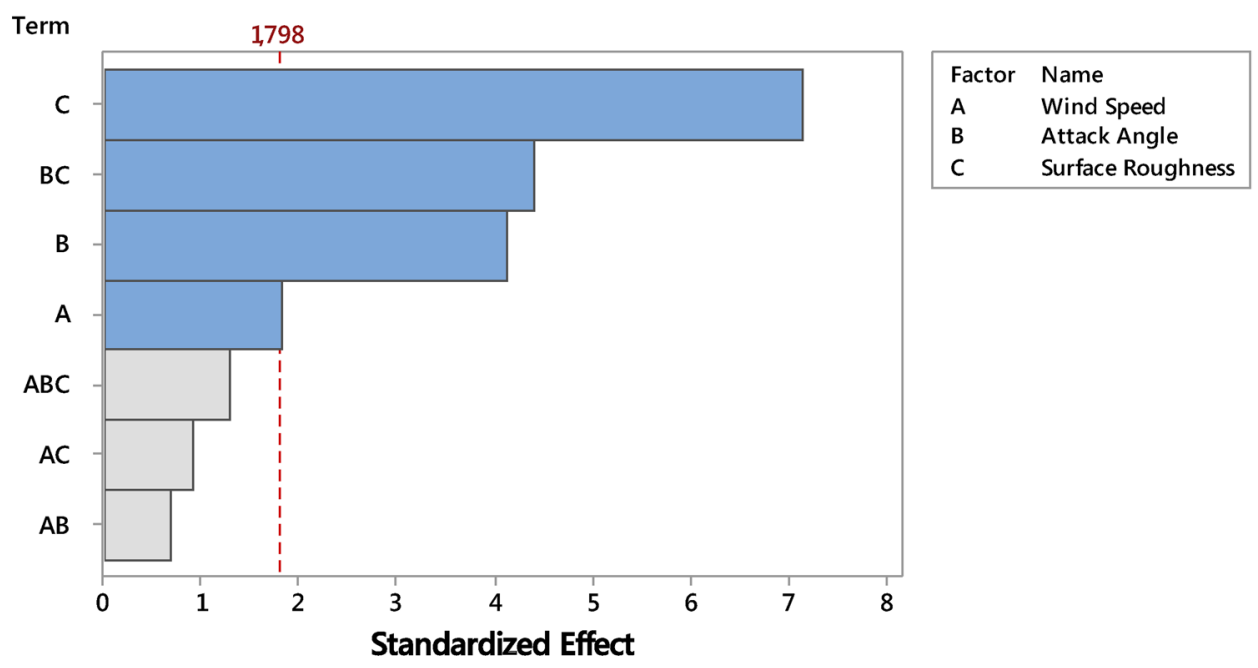

A gray bar represents a term not in the model. 
Table 6 Renewed regression analysis results

\begin{tabular}{|c|c|c|c|c|}
\hline & \multicolumn{2}{|l|}{ Step 1} & \multicolumn{2}{|l|}{ Step 2} \\
\hline & Coef & $P$ & Coef & $P$ \\
\hline Constant & 2.273 & & 2.273 & \\
\hline Wind speed & -0.260 & 0.155 & -0.260 & 0.166 \\
\hline Angle of attack & 0.590 & 0.037 & 0.590 & 0.026 \\
\hline Surface roughness & -1.020 & 0.013 & -1.020 & 0.006 \\
\hline Angle of attack $\times$ Surface roughness & -0.628 & 0.033 & -0.628 & 0.022 \\
\hline $\begin{array}{l}\text { Wind speed } \times \text { Angle of attack } \times \text { Surface } \\
\text { roughness }\end{array}$ & -0.185 & 0.253 & & \\
\hline$S$ & & 0.329014 & & 0.404269 \\
\hline$R$-sq & & $98.58 \%$ & & $96.79 \%$ \\
\hline$R$-sq (adj) & & $95.04 \%$ & & $92.52 \%$ \\
\hline$R$-sq (pred) & & $77.34 \%$ & & $77.20 \%$ \\
\hline
\end{tabular}

Table 7 Renewed variance analysis results

\begin{tabular}{llllll}
\hline Source & DF & Adj SS & Adj MS & F-Value & $P$-Value \\
\hline Model & 4 & 14.7989 & 3.6997 & 22.64 & 0.014 \\
Linear & 3 & 11.6488 & 3.8829 & 23.76 & 0.014 \\
$\quad$ Wind speed & 1 & 0.5408 & 0.5408 & 3.31 & 0.166 \\
$\quad$ Angle of attack & 1 & 2.7848 & 2.7848 & 17.04 & 0.026 \\
$\quad$ Surface roughness & 1 & 8.3232 & 8.3232 & 50.93 & 0.006 \\
2-way interactions & 1 & 3.1500 & 3.1500 & 19.27 & 0.022 \\
$\quad$ Angle of & 1 & 3.1500 & 3.1500 & 19.27 & 0.022 \\
$\quad$ attack $\times$ Surface & & & & & \\
$\quad$ roughness & & & & & \\
Error & 3 & 0.4903 & 0.1634 & & \\
Total & 7 & 15.2892 & & & \\
\hline
\end{tabular}

is obtained. As can be seen, the relationship between the variables description rate of the new model increased.

The results of the variance analysis performed for the new model revealed the contribution levels of the variables to the model. When the $p$-value of the model obtained by the variation analysis ( $F$-test) was examined $(p=0.014<0.17)$ one or more effects can be deduced (Table 7).

New regression equation:
As a result of renewed analysis, it was seen that the speed factor in the regression eq. (4) obtained has a very low effect value compared to other factors and it decreases the performance due to the fact that the coefficient $(-0.260)$ is negative (Table 8).

When the normal distribution and pareto graphs of the newly developed model were examined, it was found that the speed factor was at the boundary of the threshold value of 1.178, which is the confidence value of 0.17 and the effect was lower than other factors. However, due to the fact that the effect of wind speed on the performance is one of the factors investigated, the new regression equation will be taken into consideration.

\subsection{Verification tests}

Verification tests were performed to check the accuracy of the new regression equation. Firstly, the predictions for $C_{L} / C_{D}$ ratio were made according to the regression equation obtained for the three selected parameter (wind speed, angle of attack, and surface roughness) values.

The $C_{L} / C_{D}$ ratio was obtained as 1.215 with the regression equation as a result of the first prediction (Table 9 ).

$C_{L} / C_{D}=2.273-0.260$ Wind speed +0.590 Angle of attack-1.020 Surface roughness -0.627 Angle of attack $\times$ Surface roughness

Table $8 T$-test results and new regression equation coefficients

\begin{tabular}{lrrlrrr}
\hline Term & Effect & Coef & SE Coef & $T$-Value & $P$-Value & VIF \\
\hline Constant & & 2.273 & 0.143 & 15.90 & 0.001 & \\
Wind speed & -0.520 & -0.260 & 0.143 & -1.82 & 0.166 & 1.00 \\
Angle of attack & 1.180 & 0.590 & 0.143 & 4.13 & 0.026 & 1.00 \\
Surface roughness & -2.040 & -1.020 & 0.143 & -7.14 & 0.006 & 1.00 \\
Angle of attack $\times$ Sur- & -1.255 & -0.627 & 0.143 & -4.39 & 0.022 & 1.00 \\
$\quad$ & & & & & & \\
\hline
\end{tabular}


Table 9 First predict values and results

\begin{tabular}{llll}
\hline Variable & \multicolumn{3}{l}{ Setting } \\
\hline Wind speed & 0 & \\
Angle of attack & & 1 & \\
Surface roughness & & 1 & \\
Fit & SE Fit & $95 \% \mathrm{Cl}$ & $95 \% \mathrm{PI}$ \\
1.215 & 0.285861 & $(0.305262 ;$ & $(-0.360713 ;$ \\
& & $2.12474)$ & $2.79071)$ \\
\hline
\end{tabular}

Table 10 Second predict values and results

\begin{tabular}{|c|c|c|c|}
\hline \multicolumn{2}{|l|}{ Variable } & \multicolumn{2}{|l|}{ Setting } \\
\hline Wind speed & & 1 & \\
\hline Angle of attack & & 0 & \\
\hline Surface roughness & & -1 & \\
\hline Fit & SE Fit & $95 \% \mathrm{Cl}$ & $95 \% \mathrm{PI}$ \\
\hline 3.0325 & 0.247563 & $\begin{array}{c}(2.24464 ; \\
3.82036)\end{array}$ & $(1.52387 ; 4.54113)$ \\
\hline
\end{tabular}

Table 11 Third predict values and results

\begin{tabular}{llll}
\hline Variable & \multicolumn{3}{l}{ Setting } \\
\hline Wind speed & -1 & \\
Angle of attack & & 0 & \\
Surface roughness & & 1 & \\
Fit & SE Fit & $95 \% \mathrm{Cl}$ & $95 \% \mathrm{PI}$ \\
1.5125 & 0.247563 & $(0.724644 ;$ & $(0.0038700 ;$ \\
& & $2.30036)$ & $3.02113)$ \\
\hline
\end{tabular}

Fig. 7 Effect of main factors on performance graphs
Since the rate of variance of the regression equation in the $C_{L} / C_{D}$ ratio was $92.52 \%$, it was predicted that the predictive value would deviate by approximately $7.48 \%$ from the experimental results obtained. The testing of the first predictive results showed that the $C_{L} / C_{D}$ ratio ranged between 1.13 and 1.12 .

As a result of the second prediction (Table 10), the $C_{L} / C_{D}$ ratio was found to be 3.0325 . The values obtained from the verification tests ranged between 3.17-3.33.

As a result of the third prediction (Table 11 ), the $C_{L} / C_{D}$ ratio was found to be 1.5125 . The values obtained from the verification tests ranged between 1.42-1.50.

All three estimates were consistent with experimental data. The values found in the verification test were within the limits of the prediction.

\subsection{Factor impact assessments and surface graphs of factor interactions}

The graphs of the effects of main factors (Fig. 7) on response (wing performance) were given below. Wind speed, surface roughness and angle of attack were the factors investigated on performance. There was a slight decrease in performance with the increase of the wind speed parameter. Increase in the angle of attack was observed to increase performance. With the increase in surface roughness value, a significant decrease in performance was observed. Surface roughness delays the stall angle and decreases the lift $[4,16]$.

When the binary interaction graphs of the factors (Fig. 8) were examined, the effects of the lower and upper-level values of the factors on the result variable

\section{Main Effects Plot for CL/CD} Fitted Means

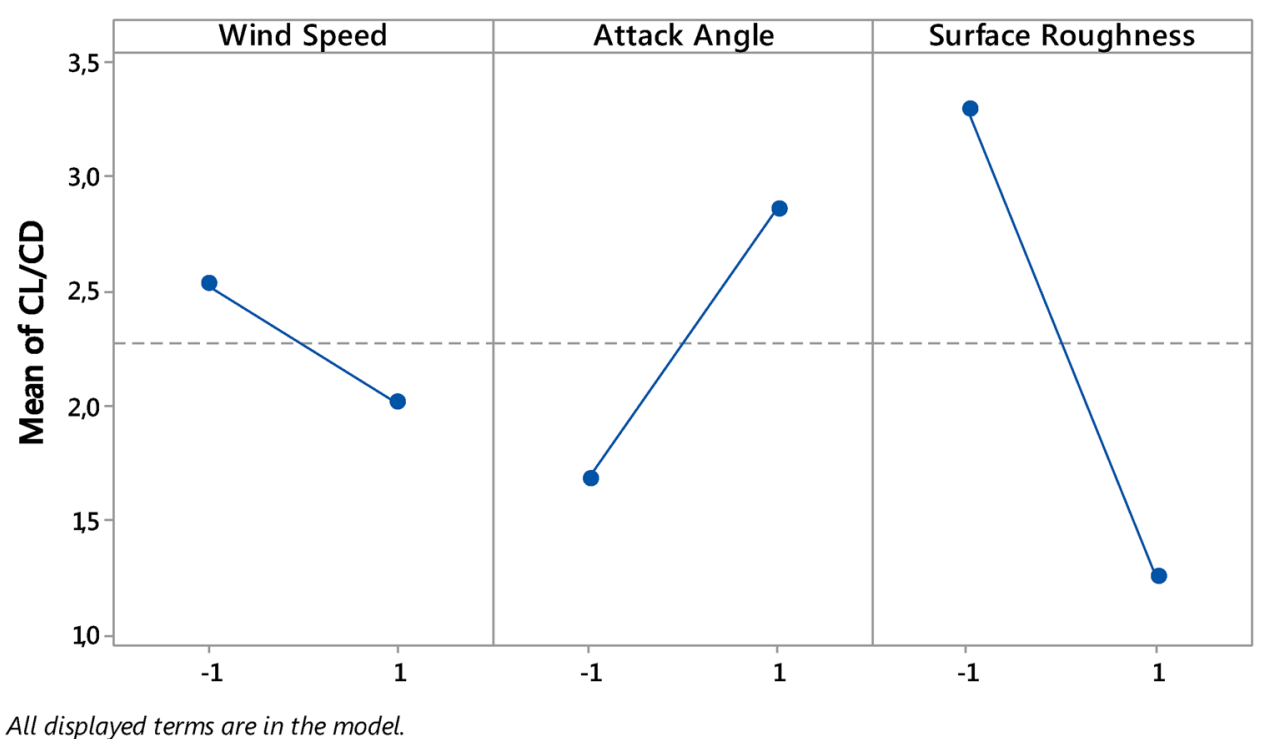

All displayed terms are in the model. 
Fig. 8 Binary factor interaction graphs
Interaction Plot for CL/CD

Means

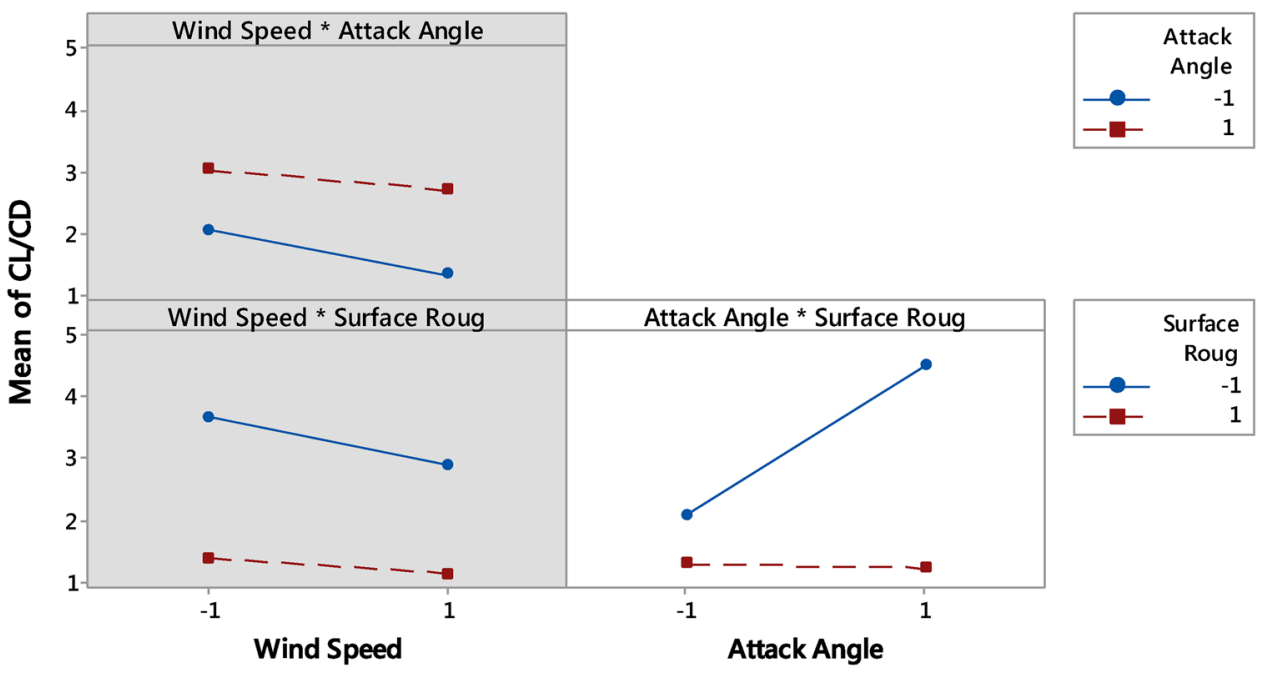

A gray background represents a term not in the model. and interactions between the two factors can be determined. Wind speed-angle of attack and wind speed-surface roughness in binary interaction graphs, level of curves were close to parallel to each other. This indicates that there is no significant interaction between these factors.

Angle of attack-surface roughness in binary interaction graph, with the increasing angle of attack and decreasing surface roughness, the curves moved away from parallelism. This indicates a binary interaction between the angle of attack and the surface roughness factors.

Wind speed-angle of attack in binary interaction; it was observed that the increase in wind speed is more effective on performance in terms of low angles of attack (decrease in performance). The effect of surface roughness is at the foreground in binary interaction between wind speed and surface roughness.

When the surface roughness was high, the wind speed had almost no effect on performance. In the case of low surface roughness, there was a slight decrease in performance with increasing wind speed. The interaction between the angle of attack and the surface roughness was the most effective binary interaction on performance. At high surface roughness, the increase in angle of attack did not affect wing performance much. At low surface roughness, the increase in angle of attack affected approximately twice the performance (increase in performance). Since the angle of attack and the surface roughness is the main factor, they have been effective for performance, but the effect of their interaction with the wind speed has been quite low. Because the best performance value was obtained at low wind speeds in both interactions. This can be explained by the fact that the selected airfoil is suitable for use in low-power wind turbines, at relatively low wind speeds, at small wing sizes (or less than $3 \mathrm{~m}$. at low turbine rotor diameters). It has been explained above that surface roughness was the most effective factor on performance [4]. Surface roughness-velocity binary interaction; the effect of the wind speed on the performance of the rough surface was very low. Increasing speed was created a loss of performance on the clean surface. On the other hand, angle of attack-wind speed interaction; the speed increase was created loss of performance regardless of the angle of attack.

The surface graphs of the design and the contour curve graphs were given below for binary interactions. The three-dimensional surface graph of the surface roughnessangle of attack binary interaction was shown in Fig. 9. Due to the interaction between the surface roughness and the angle of attack, it was seen that the $C_{L} / C_{D}$ response

\section{Surface Plot of CL/CD vs Surface Roughness; Attack Angle}

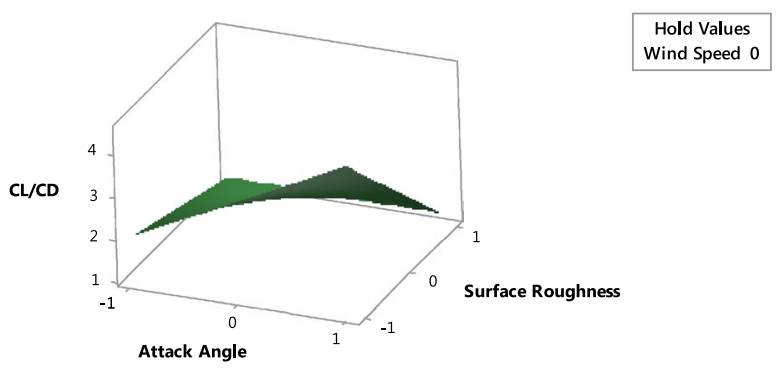

Fig. 9 Three-dimensional surface graph of the effect of surface roughness-angle of attack interaction on wing performance 
function plane was skewed. This situation shows that the surface roughness and angle of attack binary interaction were the most effective binary factor interaction on performance.

The graphs for the contour curves (Fig. 10), which define the surfaces in the three-dimensional surface graphs, were shown above. The contour curve graphs support the interaction between the surface roughness-angle of attack of the most effective binary factor interaction.

The results obtained are important in terms of shedding new light on the researches since there is no such study in the literature. In addition, in parallel with the results presented in the literature, it has emerged as the surface roughness of the most effective parameter [9-11]. The point that makes the study different from the literature is that it is revealed in its interactions between parameters.

\section{Conclusion and suggestions}

In this study, $2^{\mathrm{k}}$ factorial experimental design method was used in order to evaluate the parameters affecting the aerodynamic performance of $\$ 833$ airfoil. Wind turbine blades are generally under different operating conditions. Surfaces are subject to deterioration with the effect of natural working conditions.

Most of the time, the surface smoothness is lost due to waste. To model this situation, the surface of the airfoil is covered with a rough material. Wind speed, surface roughness and angle of attack were factors to investigate the impact on performance. Analyzes were made according to the experimental results for two levels of the factors. The effects of these factors on airfoil performance and interactions between each other were examined.

This study is the first in terms of the method used on airfoil performance analysis studies. In this maintenance, the study aims to make a unique contribution to the literature. As a result of the study;

At $a=0.1$ confidence level, the rate of explanation of the change in the system in the regression model was $88.2 \%$.A new regression model was established with $a=0.17$ confidence level and wind speed parameter was included in the model. The rate ofdefinition of the change in $C_{L} / C_{D}$ ratio of the new regression model was obtained as $92.52 \%$.

The most effective parameter on the airfoil performance is surface roughness. At both wind speeds; the clean surface airfoil performance is twice as good at the low angles of attack compared to the coated airfoil surface. The performance at high angles of attack is up to four times higher.

The second most effective factor on performance is the angle of attack-surface roughness binary factor interaction. The performance of the surface coated airfoil is reduced by approximately twice the increase in the angle of attack.

The angle of attack is the third important factor on performance. A positive increase in angle of attack has a positive effect on airfoil performance.

The least effect on performance is the wind speed. As it is understood from the coefficient in regression equation, it decreases performance.
Fig. 10 Contour plots of binary interactions of factors

\section{Contour Plots of CL/CD}
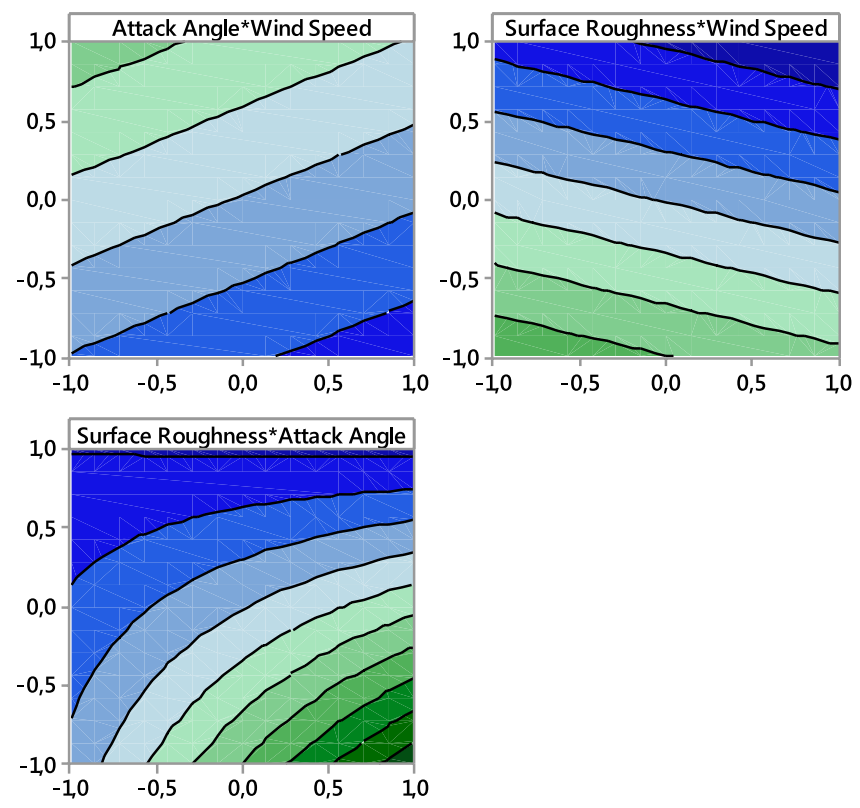

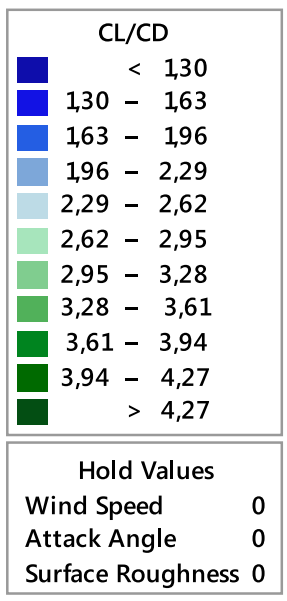

SN Applied Sciences 
Other factors; There are no significant effects on the result variable of the wind speed-angle of attack-surface roughness triple interaction, wind speed-surface roughness binary interaction, wind velocity-angle of attack binary interaction and they are not included in the regression model.

When the main factor was examined; the increase in wind speed reduces performance in both airfoil surfaces. Increase in angle of attack positively affects performance. Particularly at high wind speeds, an increase in the performance of clean surface airfoil was achieved. The increase in surface roughness is a parameter that has a negative effect on performance. In terms of high wind speed and angle of attack, a performance loss of up to fourfold was observed.

If the effect of a factor on the response variable depends on the value of the other factor, it can be considered that there is interaction between the two factors. In wind speed-angle of attack and wind speed-surface roughness, there is no significant interaction between factors. In the interaction of angle of attack-surface roughness; the improvement in surface quality with increased angle of attack results in a performance increase of approximately two times. While the angle of attack and the surface roughness are effective in the performance as the main factor, the effects of their interaction with the wind velocity are quite low. Because the change in wind speed does not make a major difference in performance compared to the change in surface condition and angle of attack. In the verification tests for checking the accuracy of the regression model, values were obtained within the estimated ranges.

The most important limitation that limits our study is the acceptance that all areas of the airfoil surface will be exposed to an equal level of pollution. In the working conditions, there was no equal amount of contamination or deterioration at each point on the airfoil surface [16]. Different scales of roughness can be applied to different parts of the airfoil surface and their effects on aerodynamic performance can be investigated [16]. Which surface areas are more susceptible to contamination can be determined by critical roughness amounts.

Furthermore, it is possible to investigate the applicability of special surface treatments to the surface during the manufacturing phase, which will minimize the possible distortion on the airfoil surface. The period during which the surface pollution will reach the critical level can be determined. For this purpose, researches can carry out on the planning and implementation of periodic cleaning procedures. On the other hand, the optimum conditions for the selected airfoil can be determined and the physical conditions at which the highest efficiency will be obtained can be determined.

\section{Compliance with ethical standards}

Conflict of interest On behalf of all authors, the corresponding author states that there is no conflict of interest.

Research involving human participants and/or animals The authors certify that the current research does not involve human participants and/or animals.

Informed consent The authors certify that they have/grant an informed consent.

\section{References}

1. Zidane IF, Saqr KM, Swadener G, Ma X, Shehadeh MF (2016) On the role of surface roughness in the aerodynamic performance and energy conversion of horizontal wind turbine blades: a review. Int J Energy Res 40(15):2054-2077

2. Sagol E, Reggio M, llinca A (2013) Issues concerning roughness on wind turbine blades. Renew Sust Energ Rev 23:514-525

3. Dalili N, Edrisy A, Carriveau R (2009) A review of surface engineering issues critical to wind turbine performance. Renew Sust Energ Rev 13(2):428-438

4. Effect of surface roughness on wind turbine performance (2017) (SANDIA Report SAND2017-10669)

5. Cohan AC, Arastoopour $\mathrm{H}$ (2016) Numerical simulation and analysis of the effect of rain and surface property on wind-turbine airfoil performance. Int J Multiphase Flow 81:46-53

6. Soltani MR, Birjandi AH, Seddighi Moorani M (2011) Effect of surface contamination on the performance of a section of a wind turbine blade. Sci Iran 18(3 B):349-357

7. Li D, Li R, Yang C, Wang X (2010) Effects of surface roughness on aerodynamic performance of a wind turbine airfoil. In: Içinde: 2010 Asia-Pacific power and energy engineering conference, $\mathrm{pp}$ 1-4. https://doi.org/10.1109/APPEEC.2010.5448702

8. Sareen A, Sapre CA, Selig MS (2014) Effects of leading edge erosion on wind turbine blade performance. Wind Energy 17(10):1531-1542

9. Ren N, Ou J (2009) Dust effect on the performance of wind turbine airfoils. J Electromagn Anal Appl 01:102

10. Liu Y, Zhang K, Tian W, Hu H (2020) An experimental investigation on the dynamic ice accretion and unsteady heat transfer over an airfoil surface with embedded initial ice roughness. Int J Heat Mass Transf 146:118900

11. Jafari K, Djavareshkian MH, Feshalami BF (2017) The effects of different roughness configurations on aerodynamic performance of wind turbine airfoil and blade. Int J Renew Energy Develop 6(3):273-281

12. Jiang $Y$, Mao ML, Deng XG, Liu HY (2015) Numerical investigation on body-wake flow interaction over rod-airfoil configuration. $J$ Fluid Mech 779:1-35

13. Bouzaher MT (2014) Numerical study of flow separation control over a NACA2415 airfoil. Int J Mech Ind Aerosp Sci 7(4):786-789. https://doi.org/10.5281/zenodo.1337257

14. Zhang $M$, Zheng ZC, Liu Y, Jiang X (2019) Numerical simulation and neural network study using an upstream cylinder for flow control of an airfoil. In ASME-JSME-KSME 2019 8th joint fluids engineering conference

15. Zhao Y, Gu W, Li Y (2018) Molecular design of 1,3,5,7-TetraCN derivatives with reduced bioconcentration using 3D-QSAR modeling, full factorial design, and molecular docking. J Mol Graph Model 84:197-214 
16. Mohammed IA, Bankole MT, Abdulkareem AS, Ochigbo SS, Afolabi AS, Abubakre OK (2017) Full factorial design approach to carbon nanotubes synthesis by CVD method in argon environment. S Afr J Chem Eng 24:17-42

17. Stanley JC (1966) The influence of Fisher's"The Design of Experiments" on educational research thirty years later. Am Educ Res J 3(3):223-229

18. Erzurumlu T, Oktem H (2007) Comparison of response surface model with neural network in determining the surface quality of moulded parts. Mater Des 28(2):459-465
19. Engineering statistics, 5th edn [Internet]. Wiley.com. [a.yer 19 Mart 2019]. Erişim adresi: https://www.wiley.com/en-us/Engin eering+Statistics\%2C+5th+Edition-p-9780470631478

20. Islam Rubel R, Kamal Uddin M, Zahìdul Islam M, Rokunuzzaman M (2017) Numerical and experimental investigation of aerodynamics characteristics of NACA 0015 aerofoil. Int J Eng Technol IJET 2(4):132-141. https://doi.org/10.19072/ijet.280499

Publisher's Note Springer Nature remains neutral with regard to jurisdictional claims in published maps and institutional affiliations. 